\title{
Conducting Workshops on Nurses' Collaboration Knowledge and Skills: Effect on Their Performance
}

\author{
Enas E. Ibraheem ${ }^{1}$, Nermin M. Eid ${ }^{2}$, Zeinab M. Rashad ${ }^{3}$ \\ ${ }^{1}$ Assistant lecturer in Nursing Administration Department, ${ }^{2}$ Professor of Nursing Administration, \\ ${ }^{3}$ lecturer of Nursing Administration, Faculty of Nursing, Menoufia University, Egypt
}

\begin{abstract}
Collaboration is an important concept in healthcare and particularly in nursing as effective nursing collaboration and teamwork contributes to improved nursing performance The purpose of the study was to assess the effect of implementing workshops for nurses to improve their knowledge and skills about collaboration and their effect on their performance at Menoufia University Hospital and National Liver Institute. Research Design: A quasi-experimental design was utilized to achieve the purpose of the current study. Sampling: All available head nurses (17) and simple random sample of staff nurses (154) working in selected units. Setting: Medical and surgical intensive care units at Shebin El-Kom Menoufia University Hospitals and National Liver Institute in Menoufia Governorate, Egypt. Instruments: Five instruments were utilized; namely; collaboration knowledge questionnaire, head nurse / nurse collaboration scale, nurse/nurse collaboration scale, observational checklist for performance of staff nurse and observational checklist for performance of head nurse. The results: There was a positive improvement in studied head and staff nurses' knowledge, skills regarding collaboration and nursing performance after implementation of workshops. Conclusion: The study concluded that there was a positive effect of the workshops for head and staff nurses on their knowledge, skills regarding collaboration and performance. Recommendations: Future studies recommended to investigate the effect of nursing collaboration on other variables such as nurses' turnover, absenteeism, and productivity.
\end{abstract}

Key words: Nursing collaboration, Knowledge, Skills, Performance, and Workshops.

\section{Introduction:}

Nowadays, great emphasis was directed toward improving collaboration among nursing personnel in an attempt to improve quality of patient care as well as decreasing medical errors through improving nursing performance (Liao, Qin, He, and Guo, 2015). Collaborative practice has been found to be of great importance especially among Intensive Care nurses, because intensive care unit
(ICU) work is complex and intense so, nurses should be prepared to deliver care to patients with important homodynamic alterations at any time, which demand specific knowledge, great skills to make decisions, and the interactions of various health care providers (Le Blanc, Schaufeli, Salanova, Lorens, and Nap, 2010). 


\section{Conducting Workshops on Nurses' Collaboration Knowledge and Skills:}

\section{Effect on Their Performance}

The nature of ICU care necessitates effective collaboration and communication amongst nurses; this promotes and allows for active participation regarding patient care and in the process, nurses respect one another and develop trust and the expertise and different contributions are acknowledged, resulting in improved quality care, patient safety and outcomes (Klopper, Coetzee, Pretorius, and Bester, 2012). Collaboration is an important concept in healthcare and particularly in nursing. In 2010, the Institute of Medicine (IOM) included collaboration as one of the recommendations in "The Future of Nursing: Leading Change, Advancing Health" report. Additionally, the American Association of Colleges of Nursing (2010) stipulated that communication and collaboration are two of the core essentials for baccalaureate and advanced practice nursing education programs.

Collaboration is defined as an interpersonal relationship between and among nursing personnel which require a high level of communication, coordination, conflict management strategies, shared process and professionalism (Dougherty and Larson, 2015).

Collaboration is a type of teamwork in which a group of people working together to achieve a common or one goal. But differ than team work in that, individuals in the group work together and feeling off one another, making decisions together, and working jointly rather than separately to achieve their own goal (Zamanzadeh, Irajpour, , Valizadeh, \& Shohani, 2014).
Effective collaboration among nursing personnel and within organizations is essential in order to provide safe, competent nursing practice, and to achieve quality patient outcomes. Nurses are expected tocollaborate with patients, with each other and with members of the health care team not only for the benefit of patients but also for the satisfaction of health care providers (Ndundu, 2015). Moreover, it's recommended to reduce medication errors and improve patient cares which in turn increase in patient safety. Accordingly, increasing collaboration among nurses is critical in maintaining a safe and effective therapeutic environment for patients (Hassona and Abd Elaziz, 2017).

When nursing personnel collaborate or work together successfully, this will promote active participation regarding patient care, share perspectives, plan together, respect one another, and support and assist each other in the interest of patient care. Hence, collaboration is a key strategy for improvement, problem solving, and innovation in the health system (Zamanzadeh, Irajpour, Valizadeh and Shohani, 2014).

However, nursing collaboration is a complex and multifaceted process that faces many barriers such as poor communication, lack of team work, role conflict, lack of problem solving skills, and inconsistencies which prevent nurses from working together effectively causing medication related problems to their patients and missed nursing care (Ndundu, 2015).

Effective collaboration and team work amongst nursing personnel emerges as 


\section{Effect on Their Performance}

fundamental components as standards of nursing performance to promote quality patient care. Improving the performance of nurses has been a topic of large interest and it is of high relevance for hospitals and nurses alike (Haddadi et al., 2015). Performance is the formal exhibition of a skill, and ability. It is the extent to which nursing personnel complete tasks, the way they utilize their available resources, and the time and energy they spend on their tasks. It is a multidimensional construct, and a dynamic concept that includes many factors affecting it (Walton and Harper, 2016).

Head nurse is a key position in health team in hospitals. The nurse manager oversees all patient nursing care in the unit in addition to acting as managing director to the other nursing staff. It is a responsibility that needs management ability as well as progressive skills in nursing. The performance of head nurse is very significant because of their strong effect on the nurses. They collaborate with most nurses on an everyday basis and must action like role models, if they role weakly and or be unsuccessful to collaborate with their nursing staff, it may affect dramatically the work performance of the nurses (Luu, 2012).

Staff nurse is one type of advanced practice nurse whose role focuses on providing services to manage the health needs of patients, families, populations, and communities. Given that collaboration is an expectation of all nurses and that Staff nurse spend much of their time partnering with head nurses to provide patient care, research is needed to understand how collaboration is constructed among these different types of nurses (Canadian Nurses Association, 2008).

Staff nurses spend more time with patients than do any other health care providers and patient outcomes are affected by nursing care quality. Thus, improvements in patient safety can be achieved by improving nurse performance. Performance evaluation in nursing is concerned with the efficiency, effectiveness, and competency of the nursing process and activities used by staff nurses in the care of patients by their head nurses (Gruman and Saks, 2011).

Education and training in collaboration is important to provide nurses with the described collaborative competencies. Nurses reported that training and education in intraprofessional collaboration led to a better understanding of one another's professional roles, responsibilities and behaviour. (Meijer, de Groot, BlaauwWesterlaken and Damoiseaux, 2016).

\section{Purpose}

The purpose of this study is to assess the effect of implementing workshops on nurses' knowledge, skills about collaboration and their performance

\section{Research Hypotheses:}

The following research hypotheses were formulated in an attempt to achieve the purpose of the study:-

1) Head and staff nurses will have higher knowledge regarding collaboration after implementation of workshops than before.

2) Head and staff nurses will have higher collaboration skills after 


\section{Effect on Their Performance}

implementation of workshops than before.

3) Head and staff nurses' performance will be significantly improved after implementing workshops regarding collaboration than before.

\section{Methods}

Research design: A quasi-experimental research design with pre, post, and follow up assessment was used in carrying out this study.

Sampling: Two different groups of studied nurses were included in this study:

- Group 1: All head nurses working in the selected medical $(\mathrm{n}=6)$ and surgical $(n=11)$ intensive care units during time of data collection at the two different hospitals. A total number was 17.

- Group 2: A simple random sample of staff * nurses were in the selected medical $(n=76)$ and surgical $(n=78)$ intensive care units during time of data collection at the two different hospitals. A total number was 154 .

Setting: This study was conducted at two different hospitals in Shebin El-Kom, Menoufia Governorate, Egypt, namely: Menoufia University Hospital and National Liver Institute. The study was conducted atselected medical and surgical intensive care units at the studied hospitals.

\section{Instruments of the study}

To achieve the purpose of this study, five instruments were used for collecting data sociodemographic instrument contained: age, gender, position, years of experiences, educational preparation, work unit, hospital and training courses / workshops.

Instrument 1: Collaboration knowledge questionnaire (pre, post, and follow up) this tool was developed and constructed by the researcher based on the review of the related literature (Almutairi 2011. Zamanzadeh 2014, Moore 2015, Assbeihat 2016, Emich 2018). It was developed to determine the level of participants' knowledge related to collaboration. It contained 50 questions divided into 25 multiple choice questions, 20 questions for true or false questions, 5 questions for matching focused on knowledge about collaboration. These 50 questions were divided on 5 sections.

\section{Scoring system of the knowledge test:}

One point was provided for each correct answer and zero for incorrect answer. The maximum total score for all questions was 50. Total scores were expressed as percentages. It was classified into three grades as the following:

1) Low knowledge level: $<75 \%$ of total score.

2) Performance level: It from 60 to $<75 \%$ of total score.

3) High knowledge level: $\geq 75 \%$ of total score.

Instrument (2): Head nurse / nurse collaboration Likert scale (pre, post, and follow up) It was developed by Stichler (2013). It contained 20 items. It was provided for both head nurses and staff nurses throughout study phases (pre, post, follow) to determine the extent of 


\section{Effect on Their Performance}

collaboration between head nurses and their staff nurses. Scoring system:

Each item was scored as follows: Two points were provided for always, one point was provided for sometimes and zero for never. The higher the total score, the higher the level of collaboration. The total score was 40 . It was classified into three levels as follows:

1) Low collaborative skills level: $<75 \%$ of total score.

2) Fair performance level: It from 60 to $<75 \%$ of total score.

3) High level of collaborative skills: $\geq 75 \%$ of total score.

\section{Instrument (3): Nurse/ nurse collaboration Likert scale (pre, post, and follow up)}

It was developed by Liao, Qin, He and $\mathrm{Gu}$ (2015). This instrument was provided for staff nurses throughout study phases (pre, post, follow) to determine the level of their collaboration skills. It consisted of four dimensions. They contained 23 items: Conflict management contained 5items, Common goals included 3items, Communication and coordination contained 7items, Professionalism and autonomy was 8 items.

Scoring system: Each item was scored as follows: Two points were provided for always; one point was provided for sometimes and zero for never. The higher the total score, the higher the level of collaboration skills. The total score was 46; it was classified into three levels as follows:
1) Low level of collaborative skills: < $75 \%$ of total score. 3) High level of collaborative skills: $\geq 75$ of total score.

2) Moderate level of collaborative skills: It from 60 to $<75 \%$ of total score.

3) High level of collaborative skills: $\geq 75$ of total score.

Instrument (4): Observational checklist for staff nurses' performance (pre, post, and follow up) It was developed by the researcher through reviewing the related literature as (Ahmed, Sleem, and Kassem 2015, Fateme and Enayatollah 2016, Abd-El Rahman and Mabourk 2017). It was provided to staff nurses throughout study phases (pre, post, follow) to assess their performance, the researcher done it by observing every staff nurse three times to ensure their level of performance at different days in morning and afternoon shifts It consisted of eight dimensions. They contained 55 items: Assessment contained 7 items, Diagnosis contained 4 items, Planning contained 4 items, Implementation included 19 items, Interpersonal relationship included 15 items; Evaluation included 2 items, Discharge plan included I item, Professional development included 3 items.

\section{Scoring system:}

Each item was scored as follows: One point if the action was done and zero if the action was not done. Total score was 55. Scores were expressed as percentages. It was classified into three levels as follows:

1) Poor performance level: < $60 \%$ of total score. 


\section{Effect on Their Performance}

2) Fair performance level: It from 60 to < 75 of total score.

3) Good performance level: $\geq 75 \%$ of total score.

Instrument (5): Observational checklist for head nurses' performance (pre, post, and follow up) It was developed by the researcher through reviewing the related literature as (AbdEl Rahman and Mabourk, 2017, Kim and Han 2019). It was provided to head nurses throughout study phases (pre, post, follow) to assess their performance, the researcher done it by observing every head nurse three times to ensure their level of performance at different days in morning and afternoon shifts. It consisted of ten dimensions. They contained 80 items: Planning included 6 items, Decision making included 4 items, Organizing contained 5 items, Time management included 14 items, Staffing contained 5 items, Leading included 10 items, Communicating and documentation contained 12 items, Motivating included 4 items , Team building included 12 items, and Evaluation contained 8 items.

Scoring system: Each item was scored as follows: One point was provided if the action was done, and zero if it was not done. The maximum total score was 80; scores were expressed as percentages it was classified into three levels as follows:

1) Poor performance level: $<60 \%$ of total score.

2) Fair performance level: It from 60 to < 75 of total score.

3) Good performance level: $\geq 75 \%$ of total score.

Validity:
A panel of seven experts was selected to test the content and face validity of the instruments. The panel included two experts from nursing administration department (Faculty of nursing, Cairo University), three experts from nursing administration department (Faculty of nursing, Tanta University), and two experts from nursing administration department (Faculty of nursing, Ana shams University). The researcher asked the panel to critique the instrument as a whole, including identifying areas of concern and reviewing the construction, flow and grammar. The panel examined the following criteria: relevant to the purpose of the study, clear and simple wording of research questions, appropriateness and comprehensiveness. Necessary modifications of some questions were done to reach the finalized version of the instruments. While they agreed on the elements, structure and scoring of instruments. The instruments were considered valid from the experts' perspective.

\section{Reliability:}

Test - retest reliability was applied by the researcher for testing the internal consistency of the instruments. It is the administration of the same instruments to the same participants under similar condition on two or more occasions. Scores from repeated testing were compared. The reliability was tested by Cronbach's alpha coefficient test. Cronbach's alphas was a $=0.881$ for instrument one, $\mathrm{a}=0.98$ for instrument two, $a=0.929$ for instrument three, and $a=0.89$ for both instrument four and instrument five.

\section{Procedure:}

An official letter was submitted from the Dean of the Faculty of Nursing to the 


\section{Effect on Their Performance}

director of National Liver Institute and the director of Menoufia University Hospital. The letter contained the title, purpose of the study, and method of data collection, data collection procedures. An interview was conducted with nurses and head nurses to explain the purpose of the study and methods of data collection. Data was collected about collaboration between head nurses and nurses and nurses with their nursing colleagues. Afterwards, an observation was done to evaluate the performance of head nurses and nurses. Points of weaknesses in the knowledge and performance of nurses and head nurses were identified and determined. Therefore, a number of workshops (12) were planned and implemented. Their objectives were.

1) Integrating the concept of nursing collaboration in nursing practice.

2) Formulating a collaborative nursing team.

3) Integrating effective collaborative communication skills among nursing members.

4) Using nursing collaboration as a strategy to manage conflict among nursing members.

5) Creating a collaborative climate among nursing members to enhance their performance.

Their titles were nature of nursing collaboration, building collaborative nursing team, collaborative communication, nursing collaboration conflict management strategy, and collaborative nursing climate. Each session in workshop lasted for two hours. Utilized methods of teaching were lectures, brainstorming, role play, case study, demonstration - re demonstration and group discussion. Workshops were conducted in the morning between 9:00 AM unit 2:00 PM At National Liver Institute and Menoufia University Hospitals. Each section started by providing a summary for the previous session and ended by thanking nurses and head nurses for their attendance. Also, verbal positive reinforcements were provided in the form of saying well done for appropriate performance and good note or very good knowledge.

A posttest for the level of knowledge and performance was done immediately after implementing workshops using the same data collection instruments. A follow up was conducted after three months.

Ethical consideration:

An official approval for conducting the study was obtained from the Ethical and Research Committee in the Faculty of Nursing, Menoufia University. Informed consent: A written informed consent was taken from participants before data collection after explaining the purpose and methods of data collection. Anonymity and confidentiality: The participants were assured that the data would be treated strictly confidentially. Furthermore, the respondents' anonymity was maintained as they would not be required to mention their names.

\section{Pilot study}

A pilot study was conducted after the development of the tool and before starting the actual data collection. The purpose of the pilot study was to ascertain clarity, relevance, applicability of the study tools and to determine obstacles that may be encountered during 


\section{Effect on Their Performance}

data collection. It also helped to estimate the time needed to fill the questionnaire sheets. The pilot study was carried on 15 staff nurses and 2 head nurses who presented $(10 \%)$ of subjects' number from the units under the study who were included in the main study sample to fill out the questionnaire. No modification was done. The time was estimated to be 20 - 25 minutes for instrument one, 1015 minutes for instrument two, 10- 15 minutes for instrument three 2025minutes for instrument four 25-30 minutes for instrument five.

\section{Statistical design:}

The data collected was categorized, tabulated, analyzed and presented in descriptive forms by using SPSS version 22. The necessary tables were then prepared and statistical analysis included the Student's t test, Wilcoxon Test, K test, $\mathrm{F}$ test, and Pearson correlation.

\section{Results}

Table 1 shows percentage distribution of the studied subjects according to their characteristics. As indicated from the table, all head nurses were female while more than half $(59.1 \%)$ of staff nurses were female. Regarding their age, more than half $(57.1 \%)$ of staff nurses were in age group ranged between 30

$<40$. The highest percentage $(70.6 \%)$ of head nurses were $30<40$. Regarding years of experiences: the highest percentage $(64.9 \%)$ of staff nurses had $5<10$ years of experiences. Nearly half $(47.1 \%)$ of head nurses had $>10$ years of experiences and $41.1 \%$ of them had $5<10 y e a r s$ of experiences. Regarding level of education: the great majority $(94.1 \%)$ of head nurses had bachelor degree in nursing while highest percentage $(60.4 \%)$ of staff nurses had associate degree in nursing. Regarding studied hospitals, more than half $(58.8 \%)$ of studied head nurses were working at the Menoufia University Hospital. Regarding attending workshop about collaboration none of head nurses had attended previously workshop about collaboration and only $14.3 \%$ of staff nurses attended previously workshop about collaboration.

Figure 1 shows knowledge levels of studied head nurses about collaboration throughout study phases.

As illustrated in this figure in preintervention phase, all of the studied head nurses had low knowledge level while at post-intervention phase the great majority $(94.1 \%)$ of them had high knowledge level and more than two thirds $(70.6 \%)$ of them had high knowledge level at follow - up.

Table 2 shows knowledge mean scores of the studied staff nurses about collaboration throughout the study phases`. As noticed in the table, there was an improvement in mean score of knowledge of staff nurses at post than pretest. Whereas, there was a decline in the follow - up scores. A highly statistical significant difference of staff nurses ' knowledge about collaboration throughout the study phases (P Value $\leq$ 0.001 ).

Figure 2 displays head nurse/ nurse collaboration skills. As shown in the figure, in pre- phase, none of the studied head nurses had high head nurse/ nurse collaboration skills level, while at postphase, approximately three quarters of studied head nurses $(76.5 \%)$ had high head nurse/ nurse collaboration skills level but there was a slight decline in head nurse/ nurse collaboration skills level at follow - up (70.6\%).

Table $\mathbf{3}$ shows nurse/ nurse collaboration skills mean scores. As noticed in the table, there was an improvement in mean score of nurse/ nurse collaborative skills of staff nurses 


\section{Effect on Their Performance}

at post $(42.84 \pm 7.03)$ than pre phase (25.98 \pm 4.77$)$. Whereas, there was slight decline in the follow up scores (39.84 \pm 10.51$)$.Moreover, there was highly statistically significant differences in staff nurses ' nurse/ nurse collaborative skills mean score throughout study phases ( $\mathrm{P}$ value $\leq$ 0.001).

Figure $\mathbf{3}$ displays head nurses' performance levels. As shown in the figure, only $17.6 \%$ of head nurses had good level of performance at pretest, while, the great majority $(88.2 \%)$ of the studied head nurses had good level of performance at posttest but there was slight decline in level of performance at follow

- up $(76.5 \%)$.

Figure $\mathbf{4}$ displays staff nurses' performance levels. As shown in the figure, only $14.9 \%$ of staff nurses had good level of performance in pre phase, while the highest percentage $(77.3 \%)$ of the studied staff nurses had good level of performance at post phase but there was slight decline in level of performance at follow - up (63\%).

Table 4 illustrates Pearson's correlation between studied head nurses' knowledge and performance scores. The results indicated that, there was positive correlation among studied head nurses' knowledge score, skills score regarding collaboration and their performance throughout study phases. This means that if the level of head nurses' knowledge and skills is high, the level of performance is expected to be high ( $\mathrm{p}$ value $<0.05,0.001)$.

Table (1): Distribution of the studied subjects according to their demographic

Characteristics $(n=171)$

\begin{tabular}{|c|c|c|c|c|}
\hline \multirow{3}{*}{ Socio demographic items } & \multicolumn{4}{|c|}{ Studied subjects $(n=171)$} \\
\hline & \multicolumn{2}{|c|}{$\begin{array}{c}\text { Head nurses } \\
(\mathrm{n}=17)\end{array}$} & \multicolumn{2}{|c|}{$\begin{array}{c}\text { Staff nurses } \\
(\mathrm{n}=154)\end{array}$} \\
\hline & $\mathbf{N}$ & $\%$ & $\mathbf{n}$ & $\%$ \\
\hline $\begin{array}{l}\text {-Age years: } \\
\qquad \begin{array}{l}\text {. } 20<30 \text { years } \\
\text {. } 30<40 \text { years } \\
\text {. }>40 \text { years }\end{array}\end{array}$ & $\begin{array}{c}0 \\
12 \\
5\end{array}$ & $\begin{array}{c}0 \% \\
70.6 \% \\
29.4 \%\end{array}$ & $\begin{array}{c}66 \\
88 \\
0\end{array}$ & $\begin{array}{c}42.9 \% \\
57.1 \% \\
0 \%\end{array}$ \\
\hline $\begin{array}{l}\text { •gender: } \\
\qquad \quad \text { Male } \\
\text { - } \text { Female }\end{array}$ & $\begin{array}{c}0 \\
17\end{array}$ & $\begin{array}{l}0.00 \% \\
100 \%\end{array}$ & $\begin{array}{l}63 \\
91\end{array}$ & $\begin{array}{l}40.9 \% \\
59.1 \%\end{array}$ \\
\hline $\begin{array}{l}\text { - Years of experience: } \\
\qquad 1<5 \text { years } \\
: \quad 5<10 \text { years } \\
:>10 \text { years }\end{array}$ & $\begin{array}{l}2 \\
7 \\
8\end{array}$ & $\begin{array}{l}11.8 \% \\
41.1 \% \\
47.1 \%\end{array}$ & $\begin{array}{c}18 \\
100 \\
36\end{array}$ & $\begin{array}{l}11.7 \% \\
64.9 \% \\
23.4 \%\end{array}$ \\
\hline $\begin{array}{l}\text { - Educational level } \\
\text { - Associated degree in nursing } \\
\text { - } \text { Bachelor degree in nursing } \\
\text { master degree in nursing }\end{array}$ & $\begin{array}{c}0 \\
16 \\
1\end{array}$ & $\begin{array}{l}0.00 \% \\
94.1 \% \\
5.9 \%\end{array}$ & $\begin{array}{c}93 \\
61 \\
0\end{array}$ & $\begin{array}{l}60.4 \% \\
39.6 \% \\
0.00 \%\end{array}$ \\
\hline $\begin{array}{l}\text { - Studied hospitals } \\
\text { - Menoufia University Hospitals } \\
\text { - National Liver Institute }\end{array}$ & $\begin{array}{c}10 \\
7\end{array}$ & $\begin{array}{l}58.8 \% \\
41.2 \% \\
\end{array}$ & $\begin{array}{l}77 \\
77\end{array}$ & $\begin{array}{l}50 \% \\
50 \% \\
\end{array}$ \\
\hline $\begin{array}{l}\text { Participate in workshop about collaboration } \\
\text { - Yes } \\
\text { - No }\end{array}$ & $\begin{array}{c}0 \\
17\end{array}$ & $\begin{array}{c}00 \% \\
100 \%\end{array}$ & $\begin{array}{c}22 \\
132\end{array}$ & $\begin{array}{l}14.3 \% \\
85.7 \%\end{array}$ \\
\hline
\end{tabular}




\section{knowledge levels of studied head}

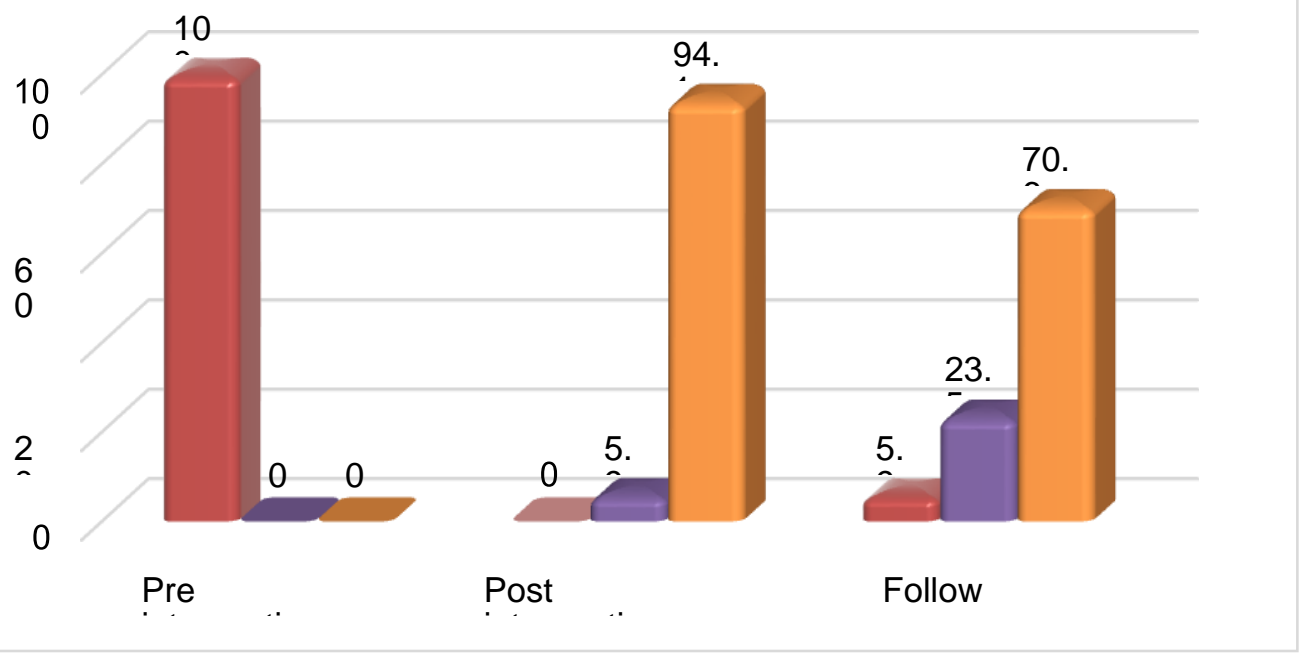

Figure (1): Knowledge levels of studied head nurses about collaboration throughout study phases.

Table (2): Knowledge mean scores of the studied staff nurses about collaboration throughout the study phases $(n=154)$

\begin{tabular}{|l|c|c|c|c|c|c|}
\hline Study phases & Pre & Post & Follow up & $\begin{array}{c}\text { Test of } \\
\text { significance }\end{array}$ & P value & Post hoc \\
\hline Mean \pm SD & $7.04 \pm 1.86$ & $40.51 \pm 11.89$ & $34.92 \pm 9.51$ & 95.6 & $<0.001 *$ & $\begin{array}{c}\text { Pre Vs Post }=<0.001 \\
\text { Pre Vs follow }=<0.001 \\
\text { Post Vs Follow }=0.001\end{array}$ \\
\hline
\end{tabular}

Level of head nurse - nurse collaboration Skill

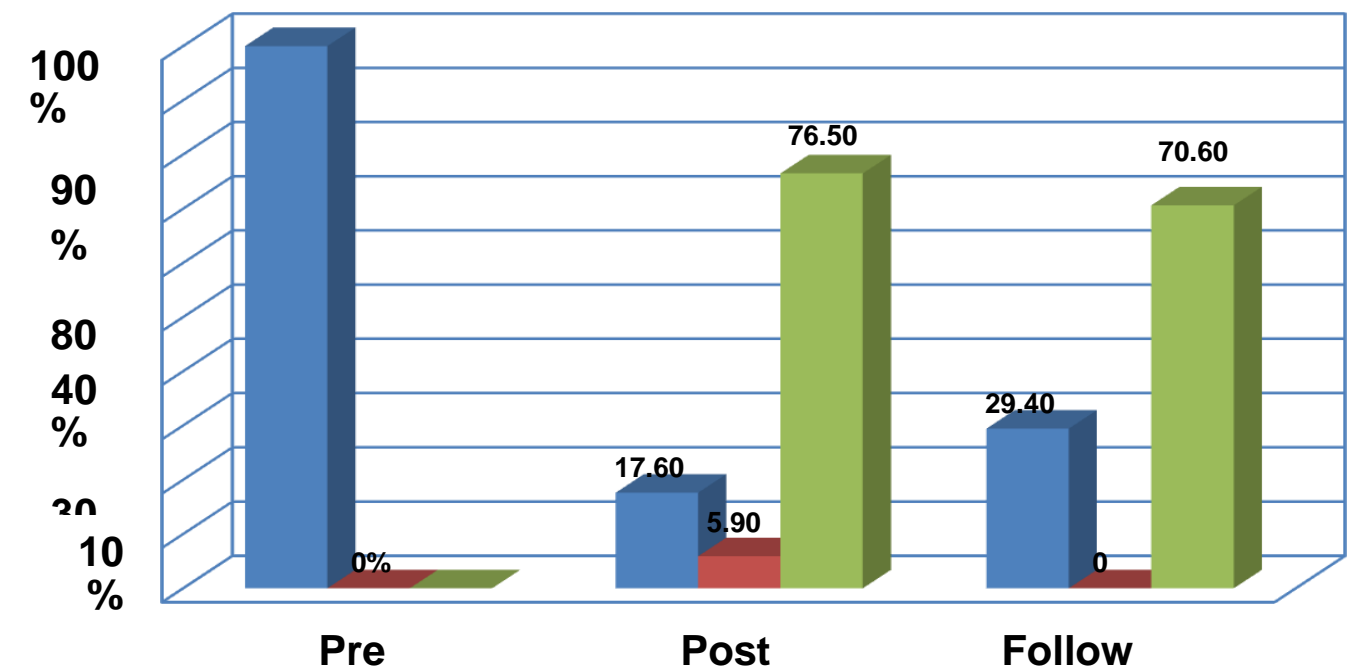

Figure (2): Head nurse- nurse collaboration skills levels throughout study phases. 
Conducting Workshops on Nurses' Collaboration Knowledge and Skills:

\section{Effect on Their Performance}

Table (3): Mean score nurse to nurse collaboration skills during the different study phases

\begin{tabular}{|c|c|c|c|c|c|c|}
\hline Study phases & Pre & Post & Follow up & $\begin{array}{c}\text { Test of } \\
\text { significance }\end{array}$ & P value & Post hoc \\
\hline Mean \pm SD & $25.98 \pm 4.77$ & $42.84 \pm 7.03$ & $39.84 \pm 10.51$ & 204.18 & $<0.001 *$ & $\begin{array}{c}\text { Pre Vs Post }=<0.001 \\
\text { Pre Vs follow }=<0.001 \\
\text { Post Vs Follow }=0.001\end{array}$ \\
\hline
\end{tabular}

Maximum score 46

*highly significant $\left(\mathrm{P}\right.$ value $\left.<\_0.001\right)$

\section{Head nurses' performance}

levels

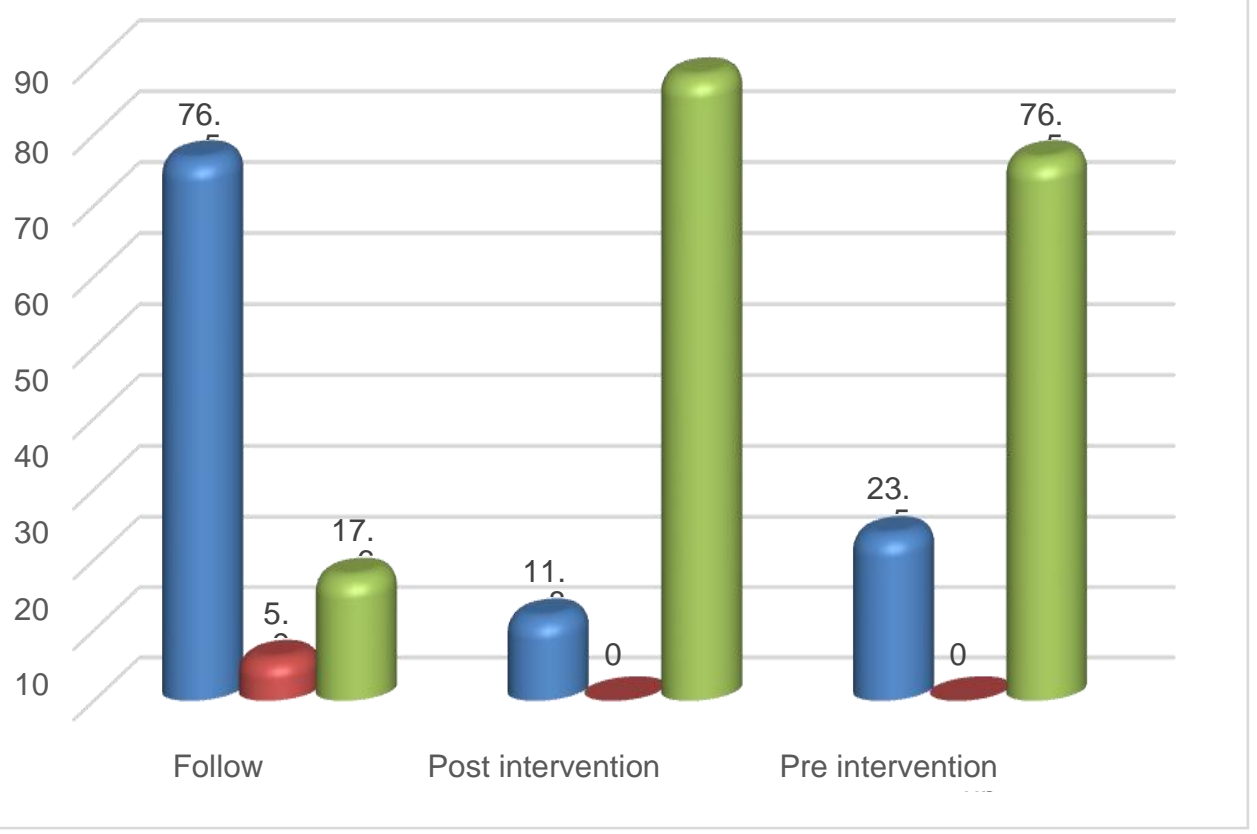

Figure (3): Head nurses' performance levels throughout study phases

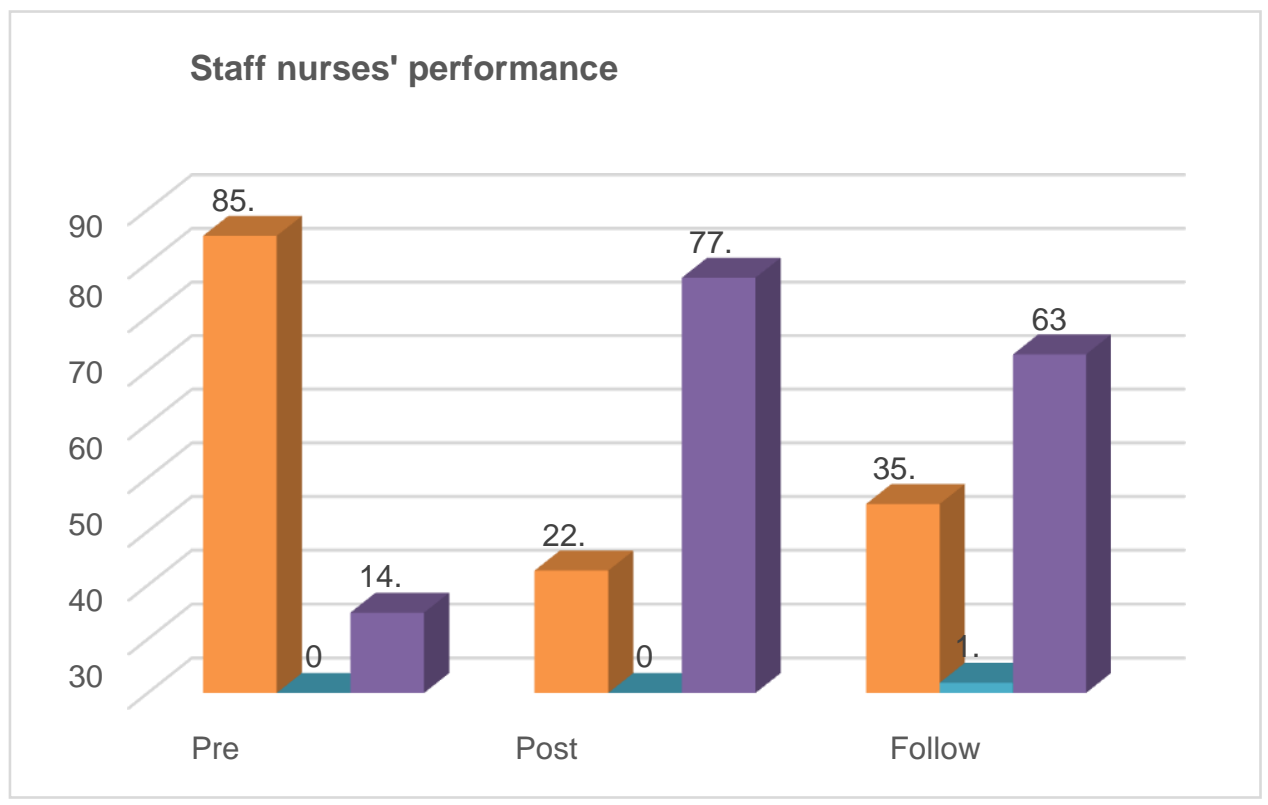

Figure (4): Staff nurses' performance levels throughout study phases 


\section{Conducting Workshops on Nurses' Collaboration Knowledge and Skills:}

\section{Effect on Their Performance}

Table (4): Correlation between studied head nurses' knowledge and skills score about collaboration and their performance $(\mathrm{N}=17)$ :

\begin{tabular}{|l|c|c|c|c|c|c|}
\hline \multirow{2}{*}{$\begin{array}{l}\text { Head nurses' knowledge and } \\
\text { skills score }\end{array}$} & \multicolumn{3}{|c|}{ Head nurses' Performance score during the study phases } \\
\cline { 2 - 7 } & \multicolumn{2}{|c|}{ pre } & \multicolumn{2}{|c|}{ Post } & \multicolumn{3}{c|}{ Follow up } \\
\hline Knowledge score & r & P value & r & P value & r & P value \\
\cline { 2 - 8 } & 0.193 & 0.018 & 0.685 & 0.002 & 0.613 & 0.009 \\
\hline Collaboration skills score & 0.242 & 0.014 & 0.779 & 0.001 & 0.495 & 0.001 \\
\hline
\end{tabular}

\section{Discussion}

The current study found that all of studied head and staff nurses had low knowledge level at pretest. This finding is in agreement with Natalie, Murdoch, Sheila and Vinek (2017) who stated that head nurses had low knowledge scores about collaboration before conducting educational training.

Moreover, Supporting to this study finding, Ya-Ya Wang, Qiao-Qin Wan, Frances Lin, Wei-Jiao Zhou, Shao-Mei Shang (2018) who conducted study about" Interventions to improve communication and collaboration between nurses and physicians in the intensive care unit" revealed that the ICU nursing staff had low knowledge about collaboration at pre-test.

The current study hypothesis stated that there will be improvement in knowledge score after conducting workshops. The study hypothesis was accepted as; there was a highly statistical significant difference in the levels of knowledge of head and staff nurses after conducting the designed workshops.

This study finding is consistent with Vazirani (2014) study, in her study "effect of a multidisciplinary intervention on communication and collaboration among physicians and nurses" revealed that an educational intervention resulted in considerable positive changes in both knowledge and skills among head nurses toward communication and collaboration. Additionally, this study finding agrees with BuljacSamardzic, Doekhie, and Wijngaarden (2020) who conducted study about "interventions to improve team effectiveness within health care" and indicated that knowledge was improved after nurses attended a specially prepared educational program. This could be attributed to the appropriate selection of teaching methods and media. On the other hand this result contradicts with Rice et al (2010) who conducted study about " An intervention to improve inter professional collaboration and communications" reported that intervention did not produce the anticipated changes in knowledge regarding communication and collaboration between health professionals. Furthermore, on the contrary, Sims, Hewitt, and Harris (2015) stated that the levels of staff nurses' knowledge were high initially and no differences in levels of knowledge were found preeducation and post-education. This could be attributed to differences in settings and work 


\section{Conducting Workshops on Nurses' Collaboration Knowledge and Skills:}

\section{Effect on Their Performance}

environments. According to the present study, head and staff nurses' knowledge has shown a slight decline at the test of follow up scores regarding collaboration three months after workshop, compared to immediate posttest but not reach total knowledge pretest score. From the researcher point of view, This due to the need for continuous training overtime and due to principles of knowledge retention. An identified principle is that knowledge retention generally falls to $75-89 \%$ of its original level after a relatively short 2-3 weeks' time (Bruno, Ongaro and Fraser, 2007).

This study finding is conformal with Mansour (2014) shown a slight decline in total knowledge follow up scores compared to the total knowledge post. Also, Herm-Barabasz (2015) stated that theoretical knowledge which not utilized in regular practice is expected to be lost with the passage of time. In contradiction to this study finding, Shahin, Attafar, and Samae. (2012) reported that there was no decline in the level of knowledge at follow up.

The current study hypothesis stated that there will be improvement in the collaboration skills between head nurses and nurses as well as between the nursing staff. The study hypothesis was accepted as; there was an actual improvement in collaboration skills between head nurses and nurses as well as between the nursing staff.

From the researcher point of view, that due to effectiveness of workshops. However, this reflected that head nurses and nurses learned to work to gather towards one common goal and to deal with different situation and problems in collaborative manner and they understood the rules and responsibilities of each.

In the same line with this study finding, Moore, Prentice , Karen, Helto, and Rhodes (2019) who conducted study about" Collaboration among registered nurses and practical nurses in acute care hospitals " found that intraprofessional collaboration(head nurse/ nurse collaboration skills )for both head nurses and their staff nurses are an essential elements of a healthy workplace environment. Conducting workshops and educational program improved these skills compared to before and this improvement is very urgent.

The current study hypothesis stated that there will be improvement of head nurses' performance which include the dimensions of " planning, , decision making, , Organizing, , time management, , staffing, , leading, , communicating and documentation, motivation, team building, and finally evaluation " immediate after conducting workshops and three months follow up the workshops than pre scores. The study hypothesis was accepted as; there was a highly statistically significant difference in head nurses ' performance score throughout the study phases. Head nurses ' performance post and follow up revealed a high significant improvement ( $p===0.001)$ in the total score of all head nurses ' performance dimensions than pre workshop.

In accordance with this study finding, study conducted by Abdelaziz and Abdo 


\section{Conducting Workshops on Nurses' Collaboration Knowledge and Skills:}

\section{Effect on Their Performance}

(2017) about " effect of management training program on nurse managers performance at a selected hospital" indicated that the program showed significant improvement in the head nurses performance and there were highly statistically significant differences among phases of the study (pretest, post-test, and follow up).

The current study hypothesis stated that there will be improvement of staff nurses ' performance which include the dimensions of " Assessment, Diagnosis, Planning, Implementation, Interpersonal relationship and Communication, Evaluation, Discharge plan and finally Professional development " immediate after conducting workshops and three months follow up the workshops than pre scores. The study hypothesis was accepted as; there was a highly statistically significant difference in staff nurses ' performance throughout the study phases. Staff nurses 'performance post and follow up revealed a high significant improvement ( $p===0.001$ ) in the total score for all performance dimensions than pre workshop.

In line with this study finding, the study conducted by Suhariyantoa, Hariyatib and Ungsianikb (2018) found training strengthening the interpersonal roles of head nurses through increase staff nurses knowledge and skills leading to improve their performance.

The current study hypothesis stated that there will be a positive correlation between studied nurses' knowledge, skills about collaboration and their nursing performance. The study hypothesis was accepted as; the results of the current study concluded that there was positive correlation between studied nurses' knowledge, skill and their nursing performance.

In the same line with the current study findings, Schmutz, Meier, and Manser( 2018) who conducted study about " The relationship between collaborative teamwork and performance in healthcare teams" stated that collaborative nursing teamwork is positively related to nursing performance. Illustrated that collaboration and teamwork relates to performance regardless of characteristics of the nursing team or task.

\section{Conclusion}

In the light of the current study findings. It is concluded that in pretest assessment, studied head and staff nurses 'knowledge and skills level regarding collaboration was low and their nursing performance was poor. Consequently, the content of workshops was developed based on need assessment of studied nurses which included comprehensive content and written handout of the workshops which served as an ongoing references. The implementation of workshops in the present study achieved improvement in the level of studied nurses' knowledge and skills about collaboration and improvement in their nursing performance at posttest with slight decline concerning their knowledge, skills, performance at follow up as compared to post test. In addition, there was a significant positive correlation 


\section{Conducting Workshops on Nurses' Collaboration Knowledge and Skills:}

\section{Effect on Their Performance}

between studied 'nurses' knowledge and skills about collaboration and their performance.

Recommendations

Based on the findings of the present study, the following recommendations are suggested: At practical and management level:

1. Healthcare organizations should work to create a culture of intra professional collaboration by making it part of their mission and utilizing intra professional practice models which support collaboration and nursing performance.

2. Nurse Managers provide a collaborative work environment and team trust to deliver healthcare effectively for better patient outcomes, thereby enhance effective intra professional collaboration and nursing performance.

3. Nursing staff should collaborate effectively with other nurses and other healthcare professionals and promote teamwork through recognition, respect and trust, role distinction, effective professional communication, inter personal skills and by recognizing the roles and scope of practice for each other to enhance collegiality.

At educational level:

1. Nursing educational department should develop inservice education, workshops and seminars to emphasize on the significance of intra professional collaboration, communication principles, team building and shared process based on need assessment and develop method of evaluation.

2. Nursing faculty should incorporate the concept of intra professional collaboration in nursing curriculum and act as role models in collaboration and communication skills in interactions with students.

\section{At research level:}

Replication of the study is needed with larger samples and different healthcare settings.

\section{REFERENCE}

Abd-El Rahman, R.,Mabourk, R., (2017). The Impact of First-Line Nurse Managers Leadership Development Training Program On Workgroup Climate And Performance

Abdelaziz, A., Abdo, A., (2017). effect of management training program on nurse managers performance at a selected hospital, International Journal of Research in Applied,Natural and Social Sciences (IMPACT: IJRANSS)ISSN (P): 2347-4580; ISSN (E): 2321-8851Vol. 5, Issue 9, Sep 2017, 121-128

Ahmed, M., Sleem, W., and Kassem, A., ( 2015). "Effect of working Condition and Fatigue on Performance of Staff Nurses at Mansoura University Hospital" IOSR Journal of Nursing and Health Science (IOSR-JNHS) eISSN: 2320-1959.p- ISSN: 23201940 Volume 4, Issue 3 Ver. V 


\section{Conducting Workshops on Nurses' Collaboration Knowledge and Skills:}

\section{Effect on Their Performance}

(May. - Jun. 2015), PP 83-91 www.iosrjournals.org

Almutairi, E S., (2011). Transformational leadership, collaborative nurse management and their relationships to staff nurse job satisfaction. Master of Science in Nursing. Faculty of San Diego State University 2011. https://sdsudspace.calstate.edu/.../ Almutairi Eman.pdf.

American Association of Colleges of Nursing Resolution, (2010). need for Collaborative Relationships Between Nursing Education and Practice, AACN, Washigton, DC, USA, 2010.

Assbeihat, J., (2016). The impact of Collaboration Among Members on Team's Performance, Management and Administrative Science Review

\section{Bruno,P.,Ongaro, $\quad$ A.,Fraser,L., (2007).LongTerm retention of material taught and examined in chiropractice curricula: its relevance to education and clinical practice, JCan Chiropr Assoc; 51: 14 - 28. 14 Bullock, R.}

Buljac-Samardzic,M., Doekhie,K., and Wijngaarden,J., (2020). "interventions to improve team effectiveness within health care, Human Resources for Health, https://doi.org/10.1186/s12960$\underline{019-0411-3}$

Canadian Nurses Association (2008): Advanced Nursing Practice: A
National Framework. Author, Ottawa, pp. 1-21.

Dougherty, M. B., Larson, E. L. (2015). The Nurse-Nurse Collaboration Scale. JONA: The Journal of Nursing Administration, 40(1), $17-$ doi:10.1097/nna.0b013e3181c47c d6.

Emich, C. (2018). Conceptualizing collaboration in nursing. Nursing Forum, 53(4), 567-573. doi:10.1111/nuf.12287

Fateme, K., and Enayatollah, S., (2016). The study of nurses' performance from the viewpoints of head nurses in the special and general wards of the instructional hospitals, Special Issue 9S: Medical Science and Healthcare: Current Scenario and Future Development, http://www.ijmrhs.com/

Gruman, J.A. Saks, A.M. (2011): "Performance management and employee engagement", Human Resource Management Review, Vol. 21, pp. 123-136.

Haddadi, M., Zakerian, S., A., Mahmoudi,M., Saraji,G.,N., Yekta, Z.,P., Aliyari, A.,(2015): Chronic fatigue syndrome prevalence and its relation to job performance among nurses. Universal Journal of Public Health. 3(1) 1-5

Hassona, F. M. H., El-Aziz, M. A. (2017): Relation between NurseNurse Collaboration and missed 


\section{Conducting Workshops on Nurses' Collaboration Knowledge and Skills:}

\section{Effect on Their Performance}

nursing care among intensive care nurses. IOSR Journal of Nursing and Health Science, 06(02), 2835 doi: $10.9790 / 1959-$ 0602092835

Herm-Barabasz, R. M. (2015). Intraprofessional Nursing Communication and Collaboration: APN-RN-Patient Bedside Rounding (Doctoral dissertation). University of Nevada, Las Vegas.

Klopper, H. C., Coetzee, S.K., Pretorius, R. Bester, P. (2012). Practice Environment, Job Satisfaction and Burnout of Critical Care Nurses in South Africa. Journal of Nursing Management, vol. 20, pp. 685-695

Le Blanc, P. M., Schaufeli, W.B., Salanova, M., B. , M., Llorens, S., Nap, R.E. (2010), Efficacy beliefs predict collaborative practice among intensive care unit nurses. Journal of Advanced Nursing, 66(3), (2010), 583-594.

Liao, C., Qin, Y., He, Y., Guo, Y. (2015). The Nurse-Nurse Collaboration Behavior Scale: Development and psychometric testing. International Journal of Nursing Science334- 339

Luu, T. $\quad$ N. K.(2012):: Training Management Skills for First-line Managers: case: company $\mathrm{X}$. Mikkeli University of applied sciences, 2012, p11.

Mansour, A., (2014). Enhancing Interdisciplinary Collaboration in Health Care (2014).
Meijer LJ, de Groot E, BlaauwWesterlaken M, Damoiseaux RA, (2016). Intraprofessional collaboration and learning between specialists and general practitioners during postgraduate training: a qualitative study. BMC Health Serv Res. 2016;16(a):376. Published 2016 Aug 11. doi:10.1186/s12913-016-1619-8

Moore, J., Prentice, D., \& Taplay, K. (2015). Collaboration: what does it really mean to nurses?. Journal of clinical nursing, 24(13-14), 2052-2054.

Moore, J. Prentice, D., Karen, Helto, N Rhodes, (2019). Medicine Nursing forum, Collaboration among registered nurses andpractical nurses in acute care hospitals: A scoping review,DOI:10.1111/nuf.12339Co rpus ID: 73486638

Natalie L. Murdoch, Sheila Epp, Jeanette Vinek (2017): Teaching andlearning activities to educate nursing students for interprofessional collaboration: A scoping review,Journal of Interprofessional Care, DOI: 10.1080/13561820.2017.1356807

Ndundu, L. D.(2015). Nurses ${ }^{\mathrm{se}}$ Perceptions Of Nurse-Nurse Collaboration In The Intensive Care Units Of A Public Sector Hospital In Johannesburg. Master dissertation, Johannesburg. (2015).

Rice, K., Zwarenstein, M., Conn, L.G., Kenaszchuk, C., Russell, A., 


\section{Effect on Their Performance}

Reeves, S., (2010). An intervention to improve interprofessional collaboration and communications: a comparative qualitative study. J. Interprofessional Care 24 (4), 350e361. http:// dx.doi.org/10.3109/135618209035 50713

Schmutz, J., Meier, L., Manser, T., (2018). " The relationship between collaborative teamwork and performance in healthcare teams, BMJ Open 2019;9:e028280. doi:10.1136/bmjopen-2018-02828

Shahin ,A., Attafar.A.,Samae,M.,(2012), An integrated approach for service quality and effectiveness improvement with a case study,

Sims, S., Hewitt, G., Harris, R. (2015). Evidence of collaboration, pooling of resources, learning and role blurring in interprofessional healthcare teams: A realist synthesis. Journal of Interprofessional Care, 29(1), 2025 doi:10.3109/13561820. 2014.939745

Stichler, J.F. (2013). The psychometric testing of the collaborative behavior scale - shortened. Paper presented at Sigma Theta Tau Research Conference, Prague, Czechoslovakia

Suhariyantoa,R., Hariyatib , T., and Ungsianikb, T.,( 2018)
"Improving the interpersonal competences of head nurses through Peplau's theoretical active learning approach" Enferm Clin. 2018;28(Supl 1 Part A):149153,http://www.elsevier.es/ enfermeriaclinica

Vazirani, S., (2014). in study about "Effect of a Multidisciplinary Intervention on Communication And Collaboration Among Physicians And Nurses. American Journal of Critical Care, January 2005, Volume 14, No. 1

Walton, J., Harper, E., (2016): Measuring nursing care value.Nurs. Econ. 34 (1), 714https://www.nursingeconomics. net/ce/ 2018/article340107.pdf.

Ya-Ya Wang, , Qiao-Qin Wan, , Frances Lin, Wei-Jiao Zhou, Shao-Mei Shang (2018) Interventions to improve communication between nurses and physicians in the intensive care unit International Journal of Nursing Sciences81e88https:// doi.org/10.1016/j.ijnss. 2017.09.00

Zamanzadeh, V., Irajpour, A., Valizadeh, L., Shohani, M.(2014). The Meaning of Collaboration, from the Perspective of Iranian Nurses: A Qualitative Study. Scientific World Journal, (2014). 